\title{
Characteristics of acute febrile illness and determinants of illness recovery among adults presenting to Singapore primary care clinics
}

Zaw Myo Tun ${ }^{1 *}$, Mahesh Moorthy ${ }^{2}$, Martin Linster ${ }^{2}$, Yvonne CF Su ${ }^{2}$, Richard James Coker ${ }^{3}$, Eng Eong Ooi ${ }^{2}$, Jenny Guek-Hong Low ${ }^{4}$, Gavin J. D. Smith ${ }^{2}$ and Clarence C. Tam ${ }^{1,3}$

\begin{abstract}
Background: Undifferentiated acute febrile illness (AFI) is a common presentation among adults in primary care settings in Singapore but large gaps exist in the understanding of the characteristics of these patients. We studied clinical and epidemiological characteristics of AFI patients and factors associated with delayed recovery from AFI.

Methods: We performed a secondary data analysis using data from the Early DENgue infection and outcome (EDEN) study on 2046 adult patients presenting at 5 Singapore polyclinics between December 2007 and February 2013 with a history of fever $\left(\geq 38^{\circ} \mathrm{C}\right)$ for less than $72 \mathrm{~h}$. We used an accelerated failure time model to investigate factors associated with delayed recovery from AFI.

Results: The mean age of patients was 36.6 years, $65 \%$ were male, $51 \%$ were of Chinese ethnicity, and $75 \%$ lived in public housing. Median illness duration was 5 days (interquartile range, 3-7). In multivariable analysis, the unemployed and white collar workers had longer illness duration compared with blue collar workers (time ratio (TR), 1.10; $95 \%$ confidence interval (Cl), 1.03-1.17 and TR, 1.08; $95 \%$ Cl, 1.02-1.15, respectively). Patients with more symptoms at initial consultation had slower recovery (TR, 1.03 per additional symptom; $95 \% \mathrm{Cl}, 1.02-1.03)$. Other clinical factors were also associated with longer duration of illness, including use of analgesics (TR, 1.21; $95 \% \mathrm{Cl}, 1.15-1.28)$; use of cough medicines (TR, 1.14; $95 \% \mathrm{Cl}, 1.08-1.20)$; use of antibiotics (TR, 1.14; $95 \% \mathrm{Cl}, 1.07-1.21$ ); and hospitalization (TR, 1.59; $95 \% \mathrm{Cl}, 1.39-1.82)$. Compared to patients with normal WBC count at first consultation, those with low WBC count had slower recovery (TR, 1.14; $95 \% \mathrm{Cl}, 1.07-1.21)$, while the reverse was observed among patients with high WBC count (TR, 0.94; $95 \% \mathrm{Cl}, 0.88-1.00)$.

Conclusions: Differences in illness duration among different types of employment may reflect differences in their underlying general health status. Early identification of factors delaying recovery could help triage management in a primary care setting. In-depth characterization of fever etiology in Singapore will improve surveillance and control activities.
\end{abstract}

Keywords: Acute febrile illness, Primary care, Undifferentiated fever

\footnotetext{
* Correspondence: zawmyotun@nus.edu.sg

${ }^{1}$ Saw Swee Hock School of Public Health, National University of Singapore,

Tahir Foundation Building, 12 Science Drive 2, \#10-01, Singapore 117549,

Singapore

Full list of author information is available at the end of the article
} 


\section{Background}

Undifferentiated acute febrile illness (AFI) is a common presentation in primary care settings and has wideranging etiologies. It is typically self-limiting with short duration and is presumed to originate from an infectious source [1]. Diagnosis of AFI is usually based on clinical features and management is empirical, due to the broad spectrum of differential diagnoses and lack of suitable point-of-care tests [2, 3].

Most studies on AFI in the Asian continent focus on distinct population subgroups, such as children $[4,5]$, hospitalized patients [6-10], pregnant women [11], and cases of fever of unknown origin (defined as core body temperature higher than $38.3^{\circ} \mathrm{C}$ on several occasions for at least 3 weeks) [12, 13]; studies on AFI in the general adult population are lacking.

Singapore is a Southeast Asian island state situated at the equator with a population of 5.47 million and a high degree of cultural diversity, trade, travel, and population migration. It is a high-income country with a high burden of febrile illnesses, including influenza and dengue [14]. Upper respiratory tract infections, often inducing fever, account for $29 \%$ of all primary care consultations in Singapore in 2010 [15]. However, large gaps exist in the understanding of the clinical and epidemiological characteristics of AFI among adults in Singapore and the Asian region. Identification of risk factors for adverse outcomes in primary care patients would allow triage management of individual cases and timely provision of healthcare at a population level. In this report, we use clinical and epidemiological data collected from patients enrolled in the Early DENgue infection and outcome (EDEN) study between 2007 and 2013 to identify factors associated with delayed illness recovery in febrile adults presenting to primary care services [16].

\section{Methods}

\section{Study population}

Singapore polyclinics are government-subsidized, comprehensive primary care clinics staffed by physicians, nurse practitioners and nurses, equipped with X-ray and laboratory services, and onsite pharmacies. The National Health Survey reported that among adult Singapore residents who consulted primary care providers, 1 in 4 accessed polyclinic services in 2010 [17].

We performed a secondary data analysis using data collected in the EDEN study, which enrolled patients above 17 years of age who presented with a history of fever $\left(\geq 38{ }^{\circ} \mathrm{C}\right)$ for less than 72 hours at any of 5 Singapore polyclinics [16]. Enrolment took place between December 2007 and February 2013. Demographic and clinical information was collected using standardized forms. Recruited subjects were followed up on 2 separate occasions, at 2-3 days and 4 weeks from the initial visit. Venous blood and/or nasopharyngeal swabs were obtained at the first and second visits for a range of laboratory diagnostics. At the last visit, participants reported the total duration of illness, defined as the selfreported number of days between symptom onset and complete recovery. For the purposes of this analysis, AFI was defined as undifferentiated fever (body temperature $\geq 38{ }^{\circ} \mathrm{C}$ ) lasting no longer than 72 hours at first presentation. Hospitalization within 5 days of study enrolment was considered to be a result of the febrile illness. Influenza-like illness (ILI) was classified according to the World Health Organization (WHO) definition [18].

\section{Statistical analysis \\ Descriptive analysis}

Discrete and continuous variables were summarized using the mean (standard deviation, SD) or median (interquartile range, IQR) as appropriate; categorical variables were summarized using frequencies and percentages. We used Kruskal-Wallis rank test to compare the medians of illness duration among categories of explanatory variables. Kaplan-Meier plots based on gender and type of employment were reported.

\section{Factors associated with delayed recovery}

Cox proportional hazards regression is commonly used to investigate factors associated with time to recovery from AFI, assuming the outcome rates are proportional over time between exposure groups. In our dataset, this proportional hazards assumption was violated for a number of explanatory variables. Instead, we used an accelerated failure time (AFT) methods to model time to recovery directly. In this framework, we investigated models assuming different distribution functions of time to recovery (Weibull, log logistic, log normal and generalized gamma). The model with the distribution that provided the smallest Akaike information criterion (AIC) estimate was determined and reported.

Demographic, clinical and laboratory variables were used as explanatory variables. Variables with a $p$-value of $<0.2$ from univariable analysis were considered in multivariable analysis. The contribution of individual variables to the multivariable model was assessed using the likelihood ratio (LR) test; variables with a LR test $p$-value $<0.05$ were retained in the model using forward stepwise exclusion. In multivariable analysis, age group, gender, and polyclinic were included as a priori potential confounding variables. The exposure variables considered are described in Table 1. For each factor we estimated the corresponding time ratios (TR) and $95 \%$ confidence interval (CI). A TR smaller than 1 means the factor is associated with longer illness duration, while a TR greater 
Table 1 Characteristics of adults with acute febrile illness presenting at the Singapore polyclinics between December 2007 and February 2013

$\begin{array}{ll}\text { Characteristics }(N=2046) \quad n(\%) & \begin{array}{l}\text { Median illness duration } P \text { value } \\ \text { in days }(\mathrm{IQR})\end{array}\end{array}$

Age groups (years)

$\begin{array}{lll}17-24 & 540(26.4) & 5(3-7) \\ 25-34 & 567(27.7) & 5(3-7) \\ 35-44 & 333(16.3) & 5(4-7) \\ 45-54 & 295(14.4) & 5(3-7) \\ 55-64 & 210(10.3) & 5.5(4-7) \\ 65 \text { and above } & 101(4.9) & 6(4-8)\end{array}$

Gender

$\begin{array}{lll}\text { Female } & 725(35.4) & 5(4-7) \\ \text { Male } & 1321(64.6) & 5(3-7)\end{array}$

Ethnicity

$\begin{array}{lll}\text { Chinese } & 1083(51.0) & 5(4-7) \\ \text { Indian } & 360(16.9) & 5(3-7) \\ \text { Malay } & 377(17.7) & 5(3-7) \\ \text { Other } & 303(14.3) & 5(4-7) \\ \text { Missing value } & 1(0.0) & \end{array}$

Body mass index

$\begin{array}{lll}<18.5 & 178(8.7) & 5(3-7) \\ 18.5-22.9 & 885(43.3) & 5(3-7) \\ 23-27.4 & 682(33.3) & 5(3-7) \\ \geq 27.5 & 301(14.7) & 5(4-7)\end{array}$

Migration status

$\begin{array}{lll}\text { Singaporean } & 1286(62.9) & 5(4-7) \\ \text { Immigrant } & 100(4.9) & 5(3-7) \\ \text { Missing value } & 3(0.1) & \end{array}$

Type of employment

$\begin{array}{lll}\text { Blue-collar } & 1086(53.1) & 5(3-7) \\ \text { White-collar } & 457(22.3) & 5(3-7) \\ \text { Other } & 54(2.6) & 6.5(4-10) \\ \text { Unemployed } & 447(21.8) & 5(4-7) \\ \text { Missing value } & 2(0.1) & \end{array}$

Housing type

$\begin{array}{lll}\text { Condominium } & 81(3.8) & 5(4-7) \\ \text { Dormitory/Hostel } & 231(10.9) & 4(3-6) \\ \text { HDB Flat } & 1588(74.8) & 5(3-7) \\ \text { Landed Property } & 135(6.4) & 5(4-7) \\ \text { Work site } & 87(4.1) & 5(4-7) \\ \text { Missing value } & 2(0.1) & \end{array}$

Hospitalization as a result of $\mathrm{AFI}$
No
$1986(97.1) \quad 5(3-7)$
Yes
$60(2.9) \quad 10(7-13)$

0.0001

0.0011

0.6460

0.0002

0.0001

0.0001
Table 1 Characteristics of adults with acute febrile illness presenting at the Singapore polyclinics between December 2007 and February 2013 (Continued)

\begin{tabular}{lll}
\hline Diabetes & & \\
No & $1952(95.4)$ & $5(3-7)$ \\
Yes & $94(4.6)$ & $6(4-8)$ \\
Temperature at initial consultation $\left({ }^{\circ} \mathrm{C}\right)$ & \\
$<38$ & $660(32.3)$ & $4(3-7)$ \\
$38-38.9$ & $999(48.9)$ & $5(4-7)$ \\
$\geq 39$ & $384(18.8)$ & $5(4-7)$ \\
Missing value & $3(0.2)$ &
\end{tabular}

WBC count at initial consultation ( $10^{3}$ cells/ $\left./ \mathrm{LL}\right)$

$$
\begin{array}{lll}
<4 \text { (Low) } & 213(10.4) & 7(4-10) \\
4-11 \text { (Normal) } & 1475(72.1) & 5(3-7) \\
>11 \text { (High) } & 345(16.9) & 4(3-7) \\
\text { Missing value } & 13(0.6) &
\end{array}
$$

Number of symptoms at initial consultation (excluding fever)

$$
\begin{array}{lll}
0-2 & 290(14.2) & 4(3-6) \\
3-4 & 515(25.2) & 5(3-7) \\
5-7 & 753(36.8) & 5(4-7) \\
8 \text { and more } & 488(23.9) & 6(4-7)
\end{array}
$$

0.0002

Severity of anemia at initial consultation ${ }^{\text {a }}$

$\begin{array}{lll}\text { No anemia } & 1821(89.0) & 5(3-7) \\ \text { Mild } & 133(6.5) & 5(4-7) \\ \text { Moderate } & 54(2.6) & 5(4-7) \\ \text { Severe } & 12(0.6) & 6(4.5-10) \\ \text { Missing value } & 26(1.3) & \end{array}$

Influenza-like illness ${ }^{\mathrm{b}}$

$\begin{array}{llll}\text { No } & 1371(67.0) & 5(3-7) & 0.0001\end{array}$

Yes

$672(32.8) \quad 5(4-7)$

Missing value $\quad 3(0.1)$

Analgesic use

$\begin{array}{llll}\text { No } & 1060(51.8) & 4(3-7) & 0.0001\end{array}$

Yes $\quad 753(36.8) \quad 6(4-7)$

Missing value $\quad 233(11.4)$

Cough medicine use

$\begin{array}{lll}\text { No } & 1213(59.3) & 4(3-7) \\ \text { Yes } & 600(29.3) & 6(4-7) \\ \text { Missing value } & 233(11.4) & \\ \text { Antibiotic use } & & \\ \text { No } & 1510(73.8) & 5(3-7) \\ \text { Yes } & 303(14.8) & 6(4-8) \\ \text { Missing value } & 233(11.4) & \end{array}$

0.0001

AFI Acute febrile illness, HDB Housing Development Board, IQR Inter-quartile range a No anaemia (male, $\geq 13$; female, $\geq 12$ ); Mild anaemia (male, 11-12.9; female, 11-11.9); Moderate anaemia (8-10.9); Severe anaemia $(<8)$ in $\mathrm{Hb}(\mathrm{g} / \mathrm{dl})[26]$

bILI: combination of symptoms including fever, cough, sore throat

${ }^{*}$ Kruskal-Wallis rank test $p$ value 
than 1 means the factor is associated with shorter illness duration compared to reference factor. Statistical analysis was performed using Stata 12 (Stata Corp).

\section{Results}

From December 2007 to February 2013, 2046 adult patients with AFI were enrolled in the EDEN study (Table 1). The mean age of patients was 36.6 years (SD, 14.8), 1321 (65\%) were male, and 1083 (51 \%) were Chinese. The percentage of fever patients aged 65 years and above was substantially higher among Chinese (8.1\%) compared to other ethnic groups $(2.6 \%, 1.4 \%$, and $0.7 \%$ among Indians, Malays, and other respectively). In terms of employment, more than half of participants $(10866,53 \%)$ were blue-collar workers, 457 (22\%) were white-collar workers, 54 (3\%) were in other employment categories (including domestic helpers, and self-employed), and 447 (21.8 \%) were not employed. The percentage of blue-collar workers was lower among Chinese (41 \%) compared to non-Chinese patients (70 \%, $53 \%$ and $83 \%$ for Indians, Malays and other ethnicities respectively).

Most patients (75 \%) lived in public housing (Housing Development Board (HDB) flats). There were 1286 (63\%) Singaporeans, with other nationalities (including Chinese, Indian, Malaysian, Bangladeshi, and other) each accounting for less than $10 \%$ of the study population. Among all patients, one-third had ILI and 60 (3\%) were hospitalized as a result of their febrile illness.

Overall median duration of illness was 5 days (IQR, $3-7)$, and rate of recovery was 1.18 cases per personweek (95\% CI, 1.13-1.24). A longer illness duration was observed among older age groups, female, Chinese ethnicity (compared to non-Chinese ethnicity) and local Singaporeans (compared to immigrants). On the other hand, a notable shorter illness duration was observed among patients who are bluecollar workers, and those who reside in dormitory or hostel (compared to those living in HDB flats) (Table 1). Figure 1 and 2 show the difference in time to recovery based on gender and type of employment. Duration of AFI reported by patients ranged from 1 to 30 days, and majority of patients recovered in the first 7 days of illness. In Fig. 1, female patients had a slower recovery compared to male patients. In Fig. 2, blue-collar workers had a faster recovery compared to other 3 employment categories.

Among the clinical factors, the illness duration was longer with the increasing number of symptoms at initial consultation. In addition, patients who reported hospitalization, presented with low WBC count at initial consultation, and those who took medications also reported longer duration of AFI (Table 1).

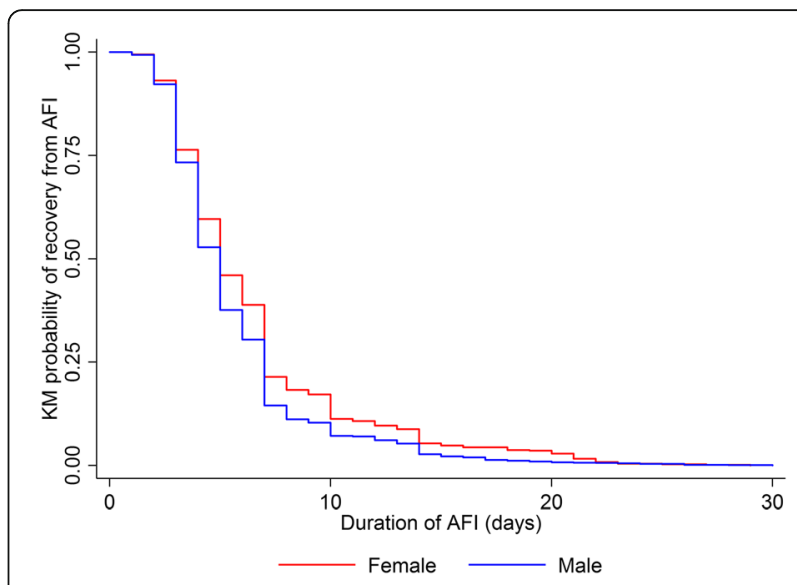

Fig. 1 Kaplan-Meier (KM) probability curves of time to acute febrile illness (AFI) recovery based on gender

Younger patients were more likely to report a greater number of symptoms at initial presentation; a quarter of fever patients aged 17-24 years reported 8 or more symptoms, compared to $11 \%$ among patients aged 65 years and above $(p=0.002)$. The distribution of symptoms reported by patients at initial consultation is presented in Table 2. Headache, muscle pain, loss of appetite, and taste alteration were the most common symptoms, each reported by more than half of all patients. Vomiting, diarrhoea, swollen lymph nodes, rashes, and bleeding occurred in $<10 \%$. No major differences in symptom distribution were observed by age group.

In multivariable analysis, the log-logistic AFT model provided the smallest AIC estimate. Compared to bluecollar workers, longer illness duration was observed among unemployed patients (TR, 1.10; $95 \%$ CI, 1.031.17) and white-collar workers (TR, 1.08; $95 \%$ CI, 1.021.15). Illness duration increased by $3 \%$ for each additional symptom reported at initial consultation (TR,

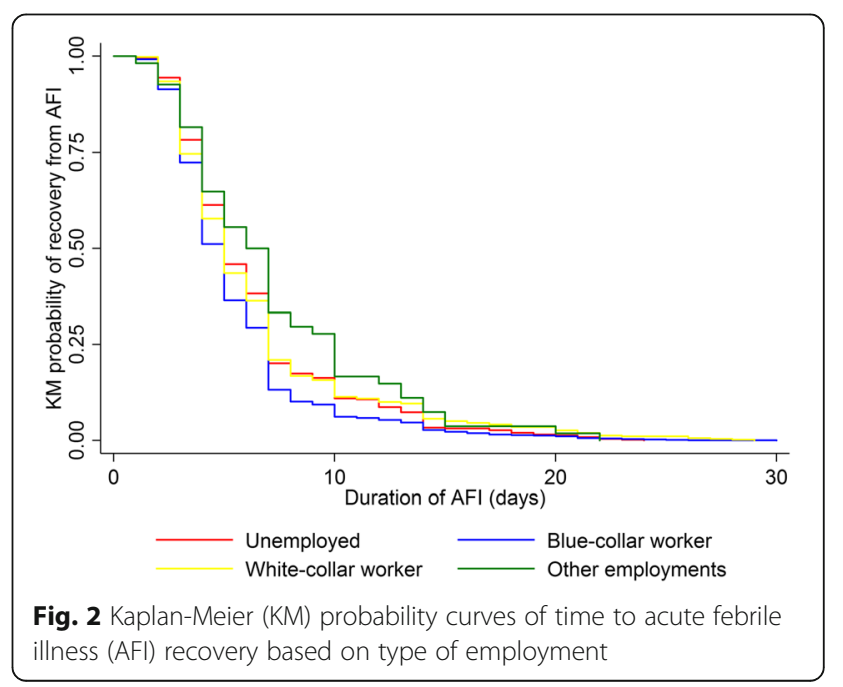


Table 2 Distribution of symptoms at initial consultation among adult patients with acute febrile illness presenting at Singapore polyclinics between December 2007 and February 2013

\begin{tabular}{|c|c|c|c|c|c|}
\hline \multirow[t]{2}{*}{ Symptom } & \multirow{2}{*}{$\begin{array}{l}\text { All patients, } \\
n(\%)\end{array}$} & \multicolumn{3}{|c|}{$n$ (\%) of patients with symptom in each age group } & \multirow[t]{2}{*}{$P$ value } \\
\hline & & $17-34$ years $(N=1107)$ & $35-64$ years $(N=838)$ & $\geq 65$ years $(N=101)$ & \\
\hline Headache & $1433(70.0)$ & $815(73.6)$ & $570(68.0)$ & $48(47.5)$ & $<0.001$ \\
\hline Muscle Pain & $1320(64.5)$ & $685(61.9)$ & $583(69.6)$ & $52(51.5)$ & $<0.001$ \\
\hline Loss of Appetite & $1158(56.6)$ & $644(58.2)$ & $464(55.4)$ & $50(49.5)$ & 0.157 \\
\hline Taste Alteration & $1037(50.7)$ & $548(49.5)$ & $440(52.5)$ & $49(48.5)$ & 0.383 \\
\hline Drowsiness & $915(44.7)$ & $517(46.7)$ & $365(43.6)$ & $33(32.7)$ & 0.017 \\
\hline Joint Pain & $810(39.6)$ & $429(38.8)$ & $352(42.0)$ & $29(28.7)$ & 0.025 \\
\hline Nausea & $544(26.6)$ & $321(29.0)$ & $210(25.1)$ & $13(12.9)$ & 0.001 \\
\hline Red Eyes & $470(23.0)$ & $259(23.4)$ & $194(23.2)$ & $17(16.8)$ & 0.320 \\
\hline Retro Orbital Pain & $331(16.2)$ & $216(19.5)$ & $111(13.3)$ & $4(4.0)$ & $<0.001^{\circ}$ \\
\hline Abdominal Pain & $323(15.8)$ & $182(16.4)$ & $129(15.4)$ & $12(11.9)$ & 0.447 \\
\hline Skin Sensitivity & $256(12.5)$ & $140(12.7)$ & $109(13.0)$ & $7(6.9)$ & 0.214 \\
\hline Vomiting & $162(7.9)$ & $92(8.3)$ & $66(7.9)$ & $4(4.0)$ & $0.322^{a}$ \\
\hline Diarrhea & $140(6.8)$ & $76(6.9)$ & $58(6.9)$ & $6(5.9)$ & 0.933 \\
\hline Swollen Lymph Nodes & $101(4.9)$ & $64(5.8)$ & $37(4.4)$ & $0(0.0)$ & $0.010^{\mathrm{a}}$ \\
\hline Rashes & $69(3.4)$ & $41(3.7)$ & $25(3.0)$ & $3(3.0)$ & $0.692^{a}$ \\
\hline Bleeding & $35(1.7)$ & $29(2.6)$ & $6(0.7)$ & $0(0.0)$ & $0.003^{\mathrm{a}}$ \\
\hline
\end{tabular}

${ }^{\text {a }}$ Fisher's exact test was employed on values less than 5

1.03 per additional symptom; $95 \% \mathrm{CI}, 1.02-1.03)$. Hospitalization was associated with almost $60 \%$ longer time to recovery (TR, 1.59; $95 \%$ CI, 1.39-1.82). Similarly, patients who reported use of analgesics (TR, 1.21; $95 \% \mathrm{CI}, 1.15-1.28$ ), cough medication (TR, 1.14; $95 \%$ CI, 1.08-1.20), and antibiotics (TR, 1.14; 95 \% CI, 1.071.21) also had significantly longer illness duration. In addition, compared to patients with normal WBC count at initial visit, those with low WBC count had slower recovery (TR, 1.14; $95 \% \mathrm{CI}, 1.07-1.21$ ), while the reverse was observed among patients with high WBC count (TR, 0.94; 95 \% CI, 0.88-1.00). (Table 3)

\section{Discussion}

This is one of only a few studies to characterize adult patients presenting to primary care with AFI. Our findings indicate that AFI in adults presenting to Singapore polyclinics is relatively mild; all patients recovered from febrile illness within 30 days and a very low percentage of hospitalization was observed. However, the burden of disease is still considerable; $50 \%$ of cases had illness lasting more than 5 days, $36 \%$ used analgesics, $29 \%$ used cough medication, and $15 \%$ used antibiotics.

The availability of data from the EDEN study, comprising a large sample of adult fever patients presenting to public primary care clinics, has provided a unique opportunity to further characterize adult fever patients. In contrast to previous studies that have focused on severely ill hospitalized patients $[6-10,19]$, our study is based on patients presenting with AFI at community polyclinics in Singapore, where there is a large burden of under-characterized illness. In addition, follow-up of fever patients allowed us to determine characteristics and factors contributing to delayed recovery in this population.

Patients who were blue-collar workers had shorter duration of illness compared to those who were unemployed or white-collar workers. A possible explanation for this is the healthy worker effect; blue collar or manual workers tend to engage in more physically demanding employment and so are likely to have better general health status, allowing them to recover faster. Information on co-morbidities was collected in the EDEN study, but co-morbidities (i.e. malignancy, and ischemic heart disease) were uncommon $(<1 \%)$ so we were unable to explore this possibility further.

Compared to older individuals, younger patients presented with more symptoms at initial consultation. A previous EDEN study using an earlier cohort also showed a similar pattern [20]. Non-specific symptoms, such as headache, drowsiness, nausea, retro orbital pain, were reported more frequently by younger patients (Table 2). Some studies have suggested that younger patients have a lower threshold for reporting symptoms [21], although this does not appear to be a consistent finding $[22,23]$.

Patients who used analgesics, cough medicines, and antibiotics had slower recovery compared to those who 
Table 3 Factors associated with delayed recovery from acute febrile illness among adult patients presenting at Singapore polyclinics between December 2007 and February 2013

\begin{tabular}{|c|c|c|c|c|}
\hline Variable $^{b}$ & Unadjusted TR $(95 \% \mathrm{Cl})$ & $P$ value & Adjusted TR $(95 \% \mathrm{Cl})$ & $P$ value \\
\hline \multicolumn{5}{|l|}{ Type of employment } \\
\hline Blue-collar workers & 1 & $<0.0001$ & 1 & 0.0035 \\
\hline White-collar workers & $1.10(1.03-1.16)$ & & $1.08(1.02-1.15)$ & \\
\hline Other & $1.29(1.11-1.51)$ & & $1.16(1.00-1.34)$ & \\
\hline Unemployed & $1.13(1.07-1.20)$ & & $1.10(1.03-1.17)$ & \\
\hline Number of symptoms at initial consultation (excluding fever) & $1.04(1.03-1.05)$ & $<0.0001^{*}$ & $1.03(1.02-1.03)$ & $<0.0001^{*}$ \\
\hline \multicolumn{5}{|l|}{ Hospitalization as a result of AFI } \\
\hline No & 1 & $<0.0001$ & 1 & $<0.0001$ \\
\hline Yes & $1.96(1.72-2.22)$ & & $1.59(1.39-1.82)$ & \\
\hline \multicolumn{5}{|l|}{ WBC count at baseline $\left(\times 10^{3}\right.$ cells $\left./ \mu \mathrm{L}\right)$} \\
\hline$<4$ (Low) & $1.35(1.25-1.46)$ & & $1.27(1.18-1.37)$ & \\
\hline 4-11 (Normal) $)^{\$}$ & 1 & $<0.0001$ & 1 & $<0.0001$ \\
\hline$>11$ (High) & $0.92(0.87-0.98)$ & & $0.94(0.88-1.00)$ & \\
\hline \multicolumn{5}{|l|}{ Analgesic use } \\
\hline No & 1 & $<0.0001$ & 1 & $<0.0001$ \\
\hline Yes & $1.21(1.15-1.27)$ & & $1.21(1.15-1.28)$ & \\
\hline \multicolumn{5}{|l|}{ Cough medicine use } \\
\hline No & 1 & $<0.0001$ & 1 & $<0.0001$ \\
\hline Yes & $1.29(1.22-1.36)$ & & $1.14(1.08-1.20)$ & \\
\hline \multicolumn{5}{|l|}{ Antibiotic use } \\
\hline No & 1 & $<0.0001$ & 1 & $<0.0001$ \\
\hline Yes & $1.21(1.13-1.29)$ & & $1.14(1.07-1.21)$ & \\
\hline
\end{tabular}

TR Time (IIlness duration) ratio, AFI Acute Febrile Illness, WBC White Blood Cells

${ }^{a}$ A TR smaller than 1 means the factor is associated with longer illness duration, while a TR greater than 1 means the factors is associated with shorter illness duration compared to reference factor

${ }^{\mathrm{b}}$ Age, gender, and polyclinic variables are adjusted for in the model as confounding factors and are not shown

* $p$ value for linear trend

did not use these medications. A similar pattern was seen among cases requiring hospitalization. The need for medications and hospitalization is likely to be an indicator of more severe illness requiring longer time for recovery.

Patients with low WBC count at initial consultation had longer duration of illness than those within the normal WBC range. Low WBC count may indicate a sub-optimal immune response to infection. This may reflect a sub-population of patients who mount generally poorer immune responses over a sustained period of time, leading to longer recovery times.

The EDEN study did not include private primary care providers. In Singapore, approximately $80 \%$ of primary care consultations take place at private healthcare providers [17]. In addition, differences in demographic characteristics may exist in the use of public and private care; only $50 \%$ of our polyclinic sample were of Chinese ethnicity, compared to $74 \%$ in the general Singapore population in 2012 [24], and $72 \%$ of fever patients lived in public HDB flats, compared to $82 \%$ in the general population in 2013 [25]. These differences underline the important contribution that private healthcare institutions can make to better understand characteristics of febrile and other diseases, both in Singapore and other settings with parallel public and private health sectors.

The primary focus of the EDEN study was dengue fever. For this reason, fever was the main criterion for enrolment, and certain respiratory symptoms, such as cough, were not systematically recorded, which could have led us to underestimate the frequency of ILI. We sought to partly validate this using additional information captured on use of cough medications.

This analysis focused on undifferentiated fever. This reflects the reality of clinical practice, in which patient management relies primarily on clinical signs and symptoms rather than microbiological diagnosis. For this reason, these findings will be of benefit for the design of policies for the management of fever patients in primary care. Dengue diagnosis in the EDEN study was low (12 \%) [20], and further testing of samples using 
multiplex assays is currently underway, which will enable us to understand the relative importance of different fever pathogens in primary care and further characterize their clinical and epidemiological features.

\section{Conclusions}

Our analyses provide some insights into the clinical characteristics and epidemiology of acute febrile illness in primary care in Singapore. Further studies that include private primary care services are important to give a fuller understanding of acute febrile illness. In addition, improved characterization of the causative agents of fever in Singapore will be useful to improve surveillance and disease control activities.

\section{Abbreviations}

AFI: Acute febrile illness; Cl: Confidence intervals; EDEN: Early DENgue infection and outcome study; HDB: Housing development board; ILI: Influenza like illness; IQR: Interquartile range; LR: Likelihood ratio; TR: Time ratio; WBC: White blood cells

\section{Acknowledgements}

The authors are very thankful to the EDEN study team for granting access to the study data for analyses.

\section{Funding}

This study was supported by a Ministry of Health, Singapore, Communicable Diseases Public Health Research Grant (MOH/CDPHRG/0012/2014).

\section{Availability of data and materials}

Data will not be shared. The authors do not have the permission for data sharing.

\section{Authors' contributions}

ZMT: Conception of the protocol, data analysis, interpretation, drafting and critically reviewing the paper. MM: Conception of the protocol, acquisition of data, interpretation, critically reviewing the paper. ML: Conception of the protocol, acquisition of data, interpretation, critically reviewing the paper. YCFS: Interpretation, critically reviewing the paper. RJC: Interpretation, critically reviewing the paper. EEO: Interpretation, critically reviewing the paper. JGHL: Interpretation, critically reviewing the paper. GJDS: Conception of the protocol, acquisition of data, interpretation, critically reviewing the paper. CCT: Conception of the protocol, data analysis, interpretation, critically reviewing the paper. All authors read and approved the final manuscript.

\section{Competing interests}

Clarence C Tam is an Associate Editor in the BMC Infectious Diseases journal. All other authors declare that they have no competing interests.

\section{Consent for publication}

Not applicable.

\section{Ethics approval and consent to participate}

Permission to analyze the data included in the current study was obtained from the EDEN study team. Ethical board exemption for this secondary data analysis study was obtained from the National Healthcare Group Domain Specific Review Board (reference number: B-14-209E).

\section{Author details}

'Saw Swee Hock School of Public Health, National University of Singapore, Tahir Foundation Building, 12 Science Drive 2, \#10-01, Singapore 117549 Singapore. ${ }^{2}$ Duke-National University of Singapore Medical School, 8 College Road, Singapore 169857, Singapore. ${ }^{3}$ London School of Hygiene and Tropical Medicine, Keppel St, London WC1E 7HT, UK. ${ }^{4}$ Department of Infectious Disease, Singapore General Hospital, Outram Road, Singapore 169608, Singapore.
Received: 6 May 2016 Accepted: 25 October 2016

Published online: 28 October 2016

\section{References}

1. Eskerud JR, Laerum E, Fagerthun H, Lunde PK, Naess A. Fever in general practice. I. Frequency and diagnoses. Fam Pract. 1992;9:263-9.

2. Phuong HL, de Vries PJ, Nagelkerke N, Giao PT, Hung LQ, Binh TQ, Nga TT, Nam NV, Kager PA. Acute undifferentiated fever in Binh Thuan province, Vietnam: imprecise clinical diagnosis and irrational pharmaco-therapy. Trop Med Int Health. 2006;11:869-79.

3. Steurer J, Held U, Spaar A, Bausch B, Zoller M, Hunziker R, Bachmann LM. A decision aid to rule out pneumonia and reduce unnecessary prescriptions of antibiotics in primary care patients with cough and fever. BMC Med. 2011;9:56.

4. Colvin JM, Muenzer JT, Jaffe DM, Smason A, Deych E, Shannon WD, Arens MQ, Buller RS, Lee W-M, Weinstock EJS, Weinstock GM, Storch GA. Detection of viruses in young children with fever without an apparent source. Pediatrics. 2012;130:e1455-62.

5. Sabchareon A, Sirivichayakul C, Limkittikul $K$, Chanthavanich $P$, Suvannadabba S, Jiwariyavej V, Dulyachai W, Pengsaa K, Margolis HS, Letson GW. Dengue infection in children in Ratchaburi, Thailand: a cohort study. I. Epidemiology of symptomatic acute dengue infection in children, 2006-2009. PLoS Negl Trop Dis. 2012;6:e1732

6. Ellis RD, Fukuda MM, McDaniel P, Welch K, Nisalak A, Murray CK, Gray MR, Uthaimongkol N, Buathong N, Sriwichai S, Phasuk R, Yingyuen K, Mathavarat C, Miller RS. Causes of fever in adults on the Thai-Myanmar border. Am J Trop Med Hyg. 2006;74:108-13.

7. Chrispal A, Boorugu H, Gopinath KG, Chandy S, Prakash JAJ, Thomas EM, Abraham AM, Abraham OC, Thomas K. Acute undifferentiated febrile illness in adult hospitalized patients: the disease spectrum and diagnostic predictors - an experience from a tertiary care hospital in South India. Trop Doct. 2010;40:230-4

8. Murdoch DR, Woods CW, Zimmerman MD, Dull PM, Belbase RH, Keenan AJ, Scott RM, Basnyat B, Archibald LK, Reller LB. The etiology of febrile illness in adults presenting to Patan hospital in Kathmandu. Nepal Am J Trop Med Hyg. 2004;70:670-5.

9. Suttinont C, Losuwanaluk K, Niwatayakul K, Hoontrakul S, Intaranongpai W, Silpasakorn S, Suwancharoen D, Panlar P, Saisongkorh W, Rolain JM, Raoult $D$, Suputtamongkol Y. Causes of acute, undifferentiated, febrile illness in rural Thailand: results of a prospective observational study. Ann Trop Med Parasitol. 2006;100:363-70.

10. Blacksell SD, Sharma NP, Phumratanaprapin W, Jenjaroen K, Peacock SJ, White NJ, Pukrittayakamee S, Day NPJ. Serological and blood culture investigations of Nepalese fever patients. Trans R Soc Trop Med Hyg. 2007; 101:686-90

11. McGready R, Ashley EA, Wuthiekanun V, Tan SO, Pimanpanarak M, ViladpaiNguen SJ, Jesadapanpong W, Blacksell SD, Peacock SJ, Paris DH, Day NP Singhasivanon P, White NJ, Nosten F. Arthropod borne disease: the leading cause of fever in pregnancy on the Thai-Burmese border. PLoS Negl Trop Dis. 2010:4:e888

12. Efstathiou SP, Pefanis AV, Tsiakou AG, Skeva II, Tsioulos DI, Achimastos AD, Mountokalakis TD. Fever of unknown origin: discrimination between infectious and non-infectious causes. Eur J Intern Med. 2010;21:137-43.

13. Vanderschueren $S$, Eyckmans T, De Munter P, Knockaert D. Mortality in patients presenting with fever of unknown origin. Acta Clin Belg. 2014;69:12-6.

14. Communicable Diseases Surveilance in Singapore. 2013. https://www.moh. gov.sg/content/moh_web/home/Publications/Reports/2014/communicablediseases-surveillance-in-singapore-2013.html. Accessed 21 Sept 2016.

15. Primary Care Survey. 2010. https://www.moh.gov.sg/content/moh_web/ home/Publications/Reports/2014/primary-care-survey-2010-report.html. Accessed 21 Sept 2016.

16. Low JGH, Ooi E-E, Tolfvenstam T, Leo Y-S, Hibberd ML, Ng L-C, Lai Y-L, Yap GSL, Li CSC, Vasudevan SG, Ong A. Early Dengue infection and outcome study (EDEN) - study design and preliminary findings. Ann Acad Med Singapore. 2006;35:783-9.

17. National Health Survey. 2010. https://www.moh.gov.sg/content/moh_web/ home/Publications/Reports/2011/national_health_survey2010.html. Accessed 21 Sept 2016.

18. WHO surveillance case definitions for ILI and SARI. http://www.who.int/ influenza/surveillance_monitoring/ili_sari_surveillance_case_definition/en/. Accessed 21 Sept 2016. 
19. Susilawati TN, MCBride WJH. Undiagnosed undifferentiated fever in Far North Queensland, Australia: a retrospective study. Int J Infect Dis. 2014;27: 59-64.

20. Low JGH, Ong A, Tan LK, Chaterii S, Chow A, Lim WY, Lee KW, Chua R, Chua CR, Tan SWS, Cheung YB, Hibberd ML, Vasudevan SG, Ng L-C, Leo YS, Ooi EE. The Early Clinical Features of Dengue in Adults: Challenges for Early Clinical Diagnosis. PLoS Negl Trop Dis. 2011;5:e1191.

21. Kjeldsberg M, Tschudi-Madsen H, Dalen I, Straand J, Bruusgaard D, Natvig B. Symptom reporting in a general population in Norway: results from the Ullensaker study. Scand J Prim Health Care. 2013;31:36-42.

22. Kroenke $\mathrm{K}$, Jackson $\mathrm{JL}$, Chamberlin J. Depressive and anxiety disorders in patients presenting with physical complaints: clinical predictors and outcome. Am J Med. 1997;103:339-47.

23. Kroenke $\mathrm{K}$, Arrington ME, Mangelsdorff AD. The prevalence of symptoms in medical outpatients and the adequacy of therapy. Arch Intern Med. 1990; 150:1685-9.

24. Population Trends 2012. Department of Statistics, Singapore. Singapore; 2012.

25. Census of Population 2010 Administrative Report. http://www.singstat.gov. sg/publications/publications-and-papers/population/census10_admin. Accessed 21 Sept 2016.

26. Haemoglobin concentrations for the diagnosis of anaemia and assessment of severity. http://www.who.int/vmnis/indicators/haemoglobin/en/. Accessed 21 Sept 2016.

Submit your next manuscript to BioMed Central and we will help you at every step:

- We accept pre-submission inquiries

- Our selector tool helps you to find the most relevant journal

- We provide round the clock customer support

- Convenient online submission

- Thorough peer review

- Inclusion in PubMed and all major indexing services

- Maximum visibility for your research

Submit your manuscript at www.biomedcentral.com/submit
Biomed Central 